\title{
Empathising and systematising in children with and without autism spectrum disorder ${ }^{1}$
}

\author{
Alev Girli ${ }^{2}$ \\ Filiz Karadağ $\breve{g}^{3}$ \\ Burak Karabey $^{4}$
}

\begin{abstract}
It is known that children with autism are insufficient in building empathy. A part of the difficulties in social interaction may originate from the lack of empathy. This research consists of two studies. First study is adaptation of the "Child Empathy Systemizing Quotient" (EQ-SQ) to Turkish culture which is prepared considering the behaviour characteristics of children in the Autism Spectrum Conditions (ASC) group, and realizing its validity and reliability. This research is conducted with 760 children with typical development processes, aged $9-16$. The findings show that the Turkish EQ-SQ is a valid and reliable tool. The second study is conducted with 112 children, 32 of them having ASC and 80 not. Through this quotient, the empathy and systematizing abilities of children with ASC are compared with their peers who demonstrate typical development processes. The EQ-SQ levels of the participants are evaluated with their mothers and their demographical values are taken from the mothers. In line with the findings in the literature, the empathy skills of children diagnosed with ASC are significantly lower than children with typical development processes. Among the children with typical development processes, females' empathy skills are shown to be significantly higher than males.
\end{abstract}

Keywords: Autism spectrum conditions; children with typical development processes; empathy; systematize; validity and reliability; sex.

\section{Introduction}

Empathy is defined as (Minio-Paluello, Lombardo, Chakrabarti, Wheelwrigth and Baron-Cohen, 2009) the process of understanding others' mental states such as intentions, wishes, wants, feelings and thoughts and it is seen an important skill in social relations. Upon examining the literature, we see that empathy consists of a fusion of two structures (Baron-Cohen \& Wheelwright, 2004; Smith, 2006). According to this, (1) cognitive empathy includes the ability to understand others' mental states and reasons thereof; especially knowing, guessing and believing them. Therefore, many researchers use the notion of cognitive empathy synonymously with the notions of theory of mind or mentalizing (Baron-Cohen \& Wheelwright, 2004; Blair, 2005); (2) affective empathy, on the other hand, is defined as the ability to respond emotionally to others (Lawrence et al., 2004, Sucksmith et al., 2013). There has been a recent increase in studies that show that individuals with autism have a greater difficulty and inability in cognitive empathy rather than emotional empathy (Baron-Cohen 2011; Mazza et al. 2014).

\footnotetext{
${ }^{1}$ A part of this study presented at 23. National Special Education Congress.

2 Assist Prof., Dokuz Eylul University, Buca Faculty of Education, Special Education Department, alev.girli@deu.edu.tr ${ }^{3}$ Research Assist., Dokuz Eylul University, Buca Faculty of Education, Special Education Department, filiz.karadag@,deu.edu.tr

${ }^{4}$ Assist Prof., Dokuz Eylul University, Buca Faculty of Education, Special Education Department, burak.karabey@deu.edu.tr
} 
Girli, A., Karadağ, F., \& Karabey, B. (2017). Empathising and systematising in children with and without autism spectrum disorder. Journal of Human Sciences, 14(1), 457-472. doi:10.14687/jhs.v14i1.4242

\subsection{Empathizing-Systemizing Theory}

Empathizing-systemizing Theory, developed by Baron-Cohen and Wheelwright (2004), claims that women have better empathy abilities, that is to say, there is a sexual difference in empathy; on the other hand, men perform better in systematizing. This research also questions why autism is 4-5 times more common in men than in women and what kind of a relation exists between autism, empathy, systematizing and sex (Baron-Cohen, Lombardo, Auyeung, Ashwin, Chakrabarti \& Knickmeyer, 2011). This theory consists of examining and logically ordering the concept of systematizing (Baron-Cohen, 2002; Baron-Cohen, Richler, Bisarya, Gurunathan, \& Wheelwright, 2003; Baron-Cohen, Knickmeyer \& Belmonte, 2005). The systematization process for any phenomena is completely regular, confined and deterministic. The explanation is certain and its value of correctness can be tested. Systematization consists of the observation of inputoutput analysis and the recognition of the rules that would realise the event $x$ with the probability $p$ (Boran-Cohen, 2002). Some systems are completely regular (such as a light switch or a mathematics formula), the variance of $100 \%$ regular events is 0 or there is only 1 degree of freedom. Therefore they can be $100 \%$ foreseen and be controlled. This enables us to predict how to manage a system when we grasp its rules. However, systematization does not help foresee the momentary changes in the behaviour of a person in social life; therefore we need empathy. Thus it is stated that systemization and empathy have different functions (Baron-Cohen, 2009; Lawson, Baron-Cohen, Wheelwright, 2004).

In order to test this theory, researches were conducted about the empathy and systematising abilities of individuals with typical development and it was found that males have better systemising cognitive style abilities whereas females have better empathising cognitive style abilities (BaronCohen, 2002). The result repeated itself in other studies conducted with individuals from varying age groups (children, young people, elderly) and it is again seen that females rank higher on empathy scores (Auyeung, Baron-Cohen, Wheelwright, Samarawickrema \& Atkinson, 2009; Wheelwright et al. 2006). Baron-Cohen et al. have developed a empathy-systematize measurement (Child Empathy-Systemizing Quotient EQ-SQ) (Baron-Cohen, Knickmeyer \& Belmonte, 2005) with which they can point out the differences in systematizing and empathy abilities between individuals on the autism spectrum and individuals with typical development. The studies show that the EQ-SQ quotient can distinguish between individuals with typical development and individuals with Asperger syndrome (Baron-Cohen \& Wheelwright, 2004; Wakabayashi et al., 2007). Individuals in the ASC group have performed well in their systematising abilities but bad in their empathising abilities (Baron-Cohen, 2009). When individuals with ASC are compared with males in their own age group (children, young people and elderly), they performed very low on empathy ability but performed better in systematizing ability (Auyeung et al., 2009; Baron-Cohen et al., 2003; Baron-Cohen and Wheelwright, 2004; Lai et al., 2011; Wheelwright et al., 2006).

\subsection{Characteristics of the Original Form of the Quotient}

Child Empathy-Systemizing Quotient: The quotient is developed by combining two different quotients for adults; namely EQ, Empathy Quotient and SQ, Systematizing Quotient by BaronCohen et al. The quotient is prepared as a parent report to be filled in by first degree relatives, generally parents. It consists of 55 articles. It is a four point Likert quotient where the lowest possible grade is 0 and the highest 100 (Lawrence et al., 2004). The validity research of the original quotient is conducted with $\mathrm{n}=1,256$ (675 female and 581 male), aged 4- 11 children with typical development and 265 children (46 female, 219 male) diagnosed with ASC. Regarding the original test, the Cronbach alpha inner consistency coefficient is 0.93 for EQ and 0.78 for SQ; Test retest reliability is 0.86 for EQ and 0.78 for SQ. Females with typical development have scored significantly higher $(\mathrm{p}<0.001)$ than males with typical development and then the group diagnosed with autism (Auyeung et al., 2009). Another study is made with 732 participants between the ages 12 and 16. The Cronbach alpha inner consistency coefficient is $(a=0.94)$ for EQ and $(a=0.89)$ for SQ. The difference of points between the group with typical development and the autism group is 
Girli, A., Karadağ, F., \& Karabey, B. (2017). Empathising and systematising in children with and without autism spectrum disorder. Journal of Human Sciences, 14(1), 457-472. doi:10.14687/jhs.v14i1.4242

proven to be statistically different $(\mathrm{F}(2,1518)=806.89, p<0.001)$ after an ANOVA variance analysis (Auyeung, Allison, Wheelwright \&Baron-Cohen, 2012).

Cultural characteristics are thought to have an effect on the measurement of empathy (Liu, Wellman, Tardif and Sabbagh, 2008). Therefore a need is observed for a new test, adapted or adjusted to the culture of the participants, to measure their empathy abilities more accurately. There is a study about the differences of empathy abilities of children with typical development process and children with autism spectrum conditions (Girli, 2012); however it is seen that this study cannot help us contribute to the understanding of the relation between sex and empathysystematize-autism which evaluates systematisation skills and empathy at the same time. This research consists of two studies. The aim of the first study is adaptation of the "Child Empathy Systemizing Quotient" (EQ-SQ) to Turkish culture and realising its validity and reliability. The aim of the second study is to examine how the different aspects of empathy and systematization abilities ASC diagnosed children and children with typical development, both having their native language as Turkish, change according to sex and age.

\section{Method}

\subsection{Participants}

Easily accessible sampling technique is used in choosing the working group (Yildirm \& Simşek, 2008). In order to provide easy access to the data of the children with typical development process, the data is collected from 5 state schools in Buca, where DEÜ Special Education Department is located.

Data of children with ASC are collected from the volunteering mothers of children who take training at two special education centres.

\subsection{Study 1: Participants}

In the first stage of the study, two different samples were used to validate the Child EmpathySystemizing Quotient. Sample 1 was involved in the pilot study, and their data was subjected to exploratory factor analysis (EFA). Sample 2 was involved in the main study, and their data was used to confirm the factor structures that were observed in EFA.

During the determination process of the participants, the variable that could have an effect on the empathy levels of the children with typical development and some prerequisites were agreed on in order to take these variables under control, in line with the related studies. Before the test, the mothers were interviewed to check the prerequisites and their approvals were obtained. The prerequisites were that (a) their developments are in line with their peers and their school achievements are above the class average, (b) they have no relatives with disabilities, (c) their native language is Turkish, (d) no language other than Turkish is spoken at their home and (e) the child started speaking not later than the age of 3 .

Data of 419 children between the ages 9 and $16(x=12.10, \mathrm{sd}=2.12)$ with typical development children made up the first working group of study 1 . These children consist of 209 $(49.9 \%)$ female and $210(50.1 \%)$ male. 68 of the children $(16.2 \%)$ are only children, 218 of them $(52 \%)$ have one sibling, 91 of them $(21.7 \%)$ have two siblings and 42 of them $(10 \%)$ have more than three siblings. 385 of the mothers $(91,9 \%)$ are married and 34 of them $(8.1 \%)$ are divorced. Their age varies between $26-61(x=39.91, \mathrm{sd}=5.79) .140$ of the mothers $(33.4 \%)$ are primary school graduates, 46 of them (11\%) are elementary school, 88 of them (21\%) high school, 129 of them $(30.8 \%)$ are university graduates and 16 of them $(3.8 \%)$ have masters' degrees. As for the income distribution, according to their own descriptions, 154 of them $(36.8 \%)$ have low income, 155 of them (37\%) have middle income and 100 of them $(26.2 \%)$ have middle-high income.

The second participant group of the study 1 consist of children $(\mathrm{N}=341)$ of whom 170 female (49.85\%) and $171(50.51 \%)$ male. 327 of the mothers are married $(95.90 \%)$ and 14 of them $(4.10 \%)$ are divorced. 120 of the mothers $(33.43 \%)$ are primary school graduates, 28 of them $(8.21 \%)$ elementary school, 68 of them (19.94\%) high school, 114 of them (33.43\%) are university 
Girli, A., Karadağ, F., \& Karabey, B. (2017). Empathising and systematising in children with and without autism spectrum disorder. Journal of Human Sciences, 14(1), 457-472. doi:10.14687/jhs.v14i1.4242

graduates and 11 of them $(3.22 \%)$ have masters' degrees. As for the income distribution, according to their own descriptions, 125 of them (36.65\%) have low income, 126 of them $(36.65 \%)$ have middle income and 90 of them $(26.39 \%)$ have middle-high income.

\subsection{Study 2: Participants}

The prerequisites to be included in the ASC group were that (a) the diagnosis is made at a university hospital by a group of expert doctors, (b) their native language is Turkish and (c) no language other than Turkish is spoken at their home. 32 children with ASC and 80 children with typically development (TD) $(n=112)$ constitute the participants of the second study. The children are between 9 and 16 years old, ASC $(X=12.09, \mathrm{sd}=2.34)$ and TD $(X=12.56, \mathrm{sd}=0.89)$. The distribution according to sex is as follows: of the TD children, 41 are (51.2\%) are female and 39 are male (48.8\%) and of the OSB children 10 are (31.2\%) female and 22 are $(68.8 \%)$ male. Statistically, for the both groups, $(t=1.53 ; \mathrm{p}=.280)$ and they do not differ. In other words, it is observed that children in the both groups have similar qualities.

\subsection{Data Collection Tools(Child Empathy-Systemizing Quotient) EQ-SQ:}

This is a four point likert type quotient that is designed to evaluate the empathizingsystemizing levels of children with the help of their parents. The answers to the test are leveled as "Completely agree", "Partly agree", "Partly disagree", "Completely disagree". For each question, an option takes 2 points, one option takes 1 point and the remaining 2 options take 0 points. The points on the grading table vary according to the question. For the whole test, a minimum of 0 and a maximum of 110 can be gathered (Auyung et al., 2009).

Empathize (EQ) consists of 27 questions. On $1^{\text {st }}, 6^{\text {th }}, 14^{\text {th }}, 18^{\text {th }}, 26^{\text {th }}, 28^{\text {th }}, 30^{\text {th }}, 31^{\text {st }}, 37^{\text {th }}, 42^{\text {nd }}$, $43^{\text {rd }}, 45^{\text {th }}, 48^{\text {th }}$ and $52^{\text {nd }}$ questions, the option "Partly Agree" is worth 1 points, "Completely Agree" is worth 2 points and the options "Partly Disagree" and "Completely Disagree" are worth 0 points. On $2^{\text {td }}, 4^{\text {th }}, 7^{\text {th }}, 9^{\text {th }}, 13^{\text {th }}, 17^{\text {th }}, 20^{\text {th }}, 23^{\text {rd }}, 33^{\text {rd }}, 36^{\text {th }}, 40^{\text {th }}, 53^{\text {rd }}$ and $55^{\text {th }}$ questions, "Partly Disagree" answers are 1 point and "Completely Disagree" answers are 2 points; whereas "Partly Agree" and "Completely Agree" answers yield no points. The highest point to be taken from these questions is 54 (Auyung et al., 2009).

Systematization (SQ), consists of 28 questions. On $5^{\text {th }}, 8^{\text {th }}, 10^{\text {th }}, 12^{\text {th }}, 19^{\text {th }}, 21^{\text {st }}, 24^{\text {th }}, 25^{\text {th }}, 29^{\text {th }}$, $34^{\text {th }}, 35^{\text {th }}, 38^{\text {th }}, 39^{\text {th }}, 41^{\text {st }}, 44^{\text {th }}, 46^{\text {th }}, 49^{\text {th }}$ and $50^{\text {th }}$ questions the answer "Partly agree" is worth 1 point and the answer "Completely Agree" are worth 2 points; whereas the answers "Partly disagree" and "Completely disagree" are worth 0 point. On $3^{\text {rd }}, 11^{\text {th }}, 15^{\text {th }}, 16^{\text {th }}, 22$ th $, 27^{\text {th }}, 32^{\text {nd }}, 47^{\text {th }}, 51^{\text {st }}$ and $54^{\text {th }}$ questions, the answer "partly disagree" is worth 1 point, "completely disagree" 2 points; whereas "partly agree" and "partly disagree" answers are worth zero points. The highest point to be taken from these questions is 56 (Auyung et al., 2009).

Personal Information Form: It is developed by the researchers to collect demographic information about the children and their parents.

\subsection{Process}

The EQ-SQ test, is a parent report quotient, therefore the data for both of the groups are collected by the researchers from mothers who are informed of the study and have given written consent. Each application lasted 15-20 minutes on average.

\subsection{Translation}

In the literature, it is noted that in the studies where individuals' characteristics are to be measured, the vocabulary or the idioms or the original language might be different and circumstances which might cause ambiguities, are best avoided (Hambleton, 2005). Considering this emphasis, the quotient was examined by two academic experts in special education and translated by two language experts to Turkish from the original language, English. Later, the translated forms from two experts are examined by 3 academics, experts in the special education field, and reduced 
Girli, A., Karadağ, F., \& Karabey, B. (2017). Empathising and systematising in children with and without autism spectrum disorder. Journal of Human Sciences, 14(1), 457-472. doi:10.14687/jhs.v14i1.4242

to one form. A back translation was conducted by two language experts different from the ones did the first translation, from Turkish to the original Language, English. The back translation and the Turkish form are compared by three experts and one expert academic in English Language Teaching and after correcting one question, the test was deemed ready to use.

\subsection{Data Analysis \\ 2.7.1. Analyses for Study 1}

In order to test whether the results from the quotient are distributed normally, we obtained a skewness of (-.366) and kurtosis of (-.477) and thus the distribution is considered normal. The condition for a normal distribution is that these values are between +2 and -2 (Büyüköztürk, Klliç Çakmak, Akgün, Karadeniz \& Demirel, 2014).

\subsubsection{Calculating Validity and Reliability}

The data collected from 760 children were analysed by means of factor structure and reliability analysis using SPSS (Statistical Package for the Social Sciences) version 21.0. A SPSS dataset was established based on the responses of these children on Child Empathy-Systemizing Quotient, and later converted to AMOS program for CFA. The purpose of this CFA was to compare these results to the factor structure/constructs emerging from the EFA in an attempt to validate the factor structure and RAS. The factor structure observed in previous step was matched with the factor structure in this step. The results of this CFA are summarized in the results section.

The article total test correlation explains the relation between total points obtained from the test and total test correlation and the points taken from the test results. A high and positive articletotal correlation shows that articles exemplify similar behaviours and the inner consistency is high (Büyüköztürk, 2009). A correlation based article analysis is conducted with the purpose to determine the distinctiveness of the articles of EQ-SQ and to what extent each article is to the same purpose with the whole test.

In line with the obtained structural validity data, sub quotients are calculated in order to determine the reliability of the EQ-SQ quotient and the Cronbach alpha coefficient of the whole quotient.

\subsubsection{Analyses done for Study 2}

A one sided ANOVA is performed is order to determine whether it can distinguish children with TD and with ASC (whether there is a difference according to diagnosis) and whether the points for TD and ASC children differ according to sex.

\section{Findings}

First, the validity and reliability findings of the EQ-SQ of Study 1 are presented. Later, the findings which compare the empathy levels of children in the ASC group and those in the TD group according to their diagnoses and sex, as elaborated in Study 2.

\subsection{Study 1}

The total points taken from the EQ-SQ test by the children with TD who took part in adaptation and validity-reliability study, minimum and maximum points taken from empathy and systematizing sub quotients are presented in Table 1. 
Girli, A., Karadağ, F., \& Karabey, B. (2017). Empathising and systematising in children with and without autism spectrum disorder. Journal of Human Sciences, 14(1), 457-472. doi:10.14687/jhs.v14i1.4242

Table 1. Completive statistics of total Empathy EQ-SQ points, systematizing and empathising points of children with typical development

\begin{tabular}{lccccc}
\hline & $\mathrm{N}$ & Minimum & Maximum & Mean & SS \\
\hline EQ & 760 & 10,89 & 66,00 & 39,2236 & 9,32452 \\
SQ & 760 & 5,00 & 48,00 & 27,9336 & 8,06927 \\
Total EQ-SQ & 760 & 17,89 & 100,00 & 67,1573 & 14,97044 \\
\hline
\end{tabular}

\subsubsection{Structural validity and reliability results of EQ-SQ quotient: Factor Analysis}

EQ-SQ empathy sub quotient is developed from an adult empathy quotient prepared for adults as a single factor. However, the factor analytic studies of the adult quotient in different languages (Andrew, Cooke \& Muncer, 2008; Gouveia, Milfont, Gouveia, Neto \& Galvão, 2012; Lawrence at al., 2004; Muncer \& Ling, 2006) show that the quotient consists of three factors that measure "cognitive empathy", "emotional empathy" and "social skills". Therefore an exploratory factor analysis is performed as it is thought that it would enable us to make evaluations on the subsections of empathy in this study as well.

Before the factor analysis, the suitability of the data for the factor analysis is tested with Kaiser-Meyer-Olkin and Bartlet tests. For the factor analysis of 27 articles, KMO values is found 0,821 and the Bartlett test result is found to be $\chi^{2}=1957,253$ ( $\left.\mathrm{p} \leq .05\right)$. A minimum KMO value of 0.60 is recommended in order to conduct a factor analysis on data (Pallant, 2001). The observed KMO value of 821 is higher than the recommended $\mathrm{KMO}$ and it shows that the data is suitable for factor analysis. As a result of the first explanatory factor analysis, $4^{\text {th }}, 17^{\text {th }}$ and $53^{\text {td }}$ questions which had a factor load under 0,30 were excluded. The suitability for the remaining data for factor analysis is tested with Kaiser-Meyer-Olkin and Bartlet tests. The KMO value for the factor analysis of the remaining 24 questions is found to be .829 and the result of Bartlett test is $\chi^{2}=1832,370(\mathrm{p} \leq .05)$. Factor pattern of the empathy questions of EQ-SQ quotient is presented in Figure 2. The first factor is named "emotional empathy". The break point of this factor is .39 and it consists of 11 questions. The second factor is named "cognitive empathy", its break point is .30 consists of 13 questions.

Table 2. Empathy Quotient Factor Pattern

\begin{tabular}{lll}
\hline Item & Factor 1 emotion & Factor 2 cognitive \\
\hline Item 55 &, 653 & \\
Item 40 &, 606 & \\
Item 20 &, 606 & \\
Item 33 &, 593 & \\
Item 36 &, 590 & \\
Item 23 &, 523 & \\
Item 9 &, 461 & \\
Item 30 &, 446 & \\
Item 13 &, 428 & \\
Item 7 &, 398 &, 633 \\
Item 2 &, 391 &, 580 \\
Item 52 & & \\
Item 37 & & \\
\hline
\end{tabular}


Girli, A., Karadağ, F., \& Karabey, B. (2017). Empathising and systematising in children with and without autism spectrum disorder. Journal of Human Sciences, 14(1), 457-472. doi:10.14687/jhs.v14i1.4242

\begin{tabular}{ll}
\hline Item 48 &, 547 \\
Item 31 &, 543 \\
Item 14 &, 542 \\
Item 26 &, 517 \\
Item 28 &, 500 \\
Item 18 &, 473 \\
Item 42 &, 450 \\
Item 45 &, 405 \\
Item 1 &, 345 \\
Item 43 &, 328 \\
Item 6 &, 309 \\
\hline
\end{tabular}

results obtained from the Explanatory factor analysis are evaluated for model conformity indices with the AMOS software. At the end of the first level DFA analysis of the empathy

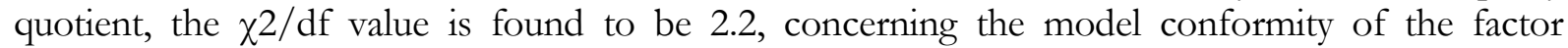
structure consisting of 24 questions and two sub factors. Compatibility index values are NFI: .85, CFI: .88, GFI: .90. The fact that the $\chi 2 / \mathrm{df}$ value is lower than 3 shows that the model compatibility is good. CFI, NFI and RFI values close to 0.90 are acceptable (Hu and Bentler, 1998).

In order to increase the model compatibility of the quotient, $1^{\text {st }}, 18^{\text {th }}$ and $43^{\text {rd }}$ questions are dropped based on their "Standardized Regression Weights" and covariance are built between all the remaining questions according to DFA results. After this process, a second CFA analysis is made and the $\chi^{2 / d f}$ value regarding the model compatibility of the factor structure containing two sub factors is found to be 1.9. Considering these results, the $\chi^{2 / d f}$, NFI, CFI, GFI values of the confirmatory factor analysis of the Empathy Quotient are found to be acceptable. The Path diagram of the first level DFA regarding the Empathy quotient is given in Chart 1.

\section{Chart 1. Two Factor Structure Model of Empathy Quotient}

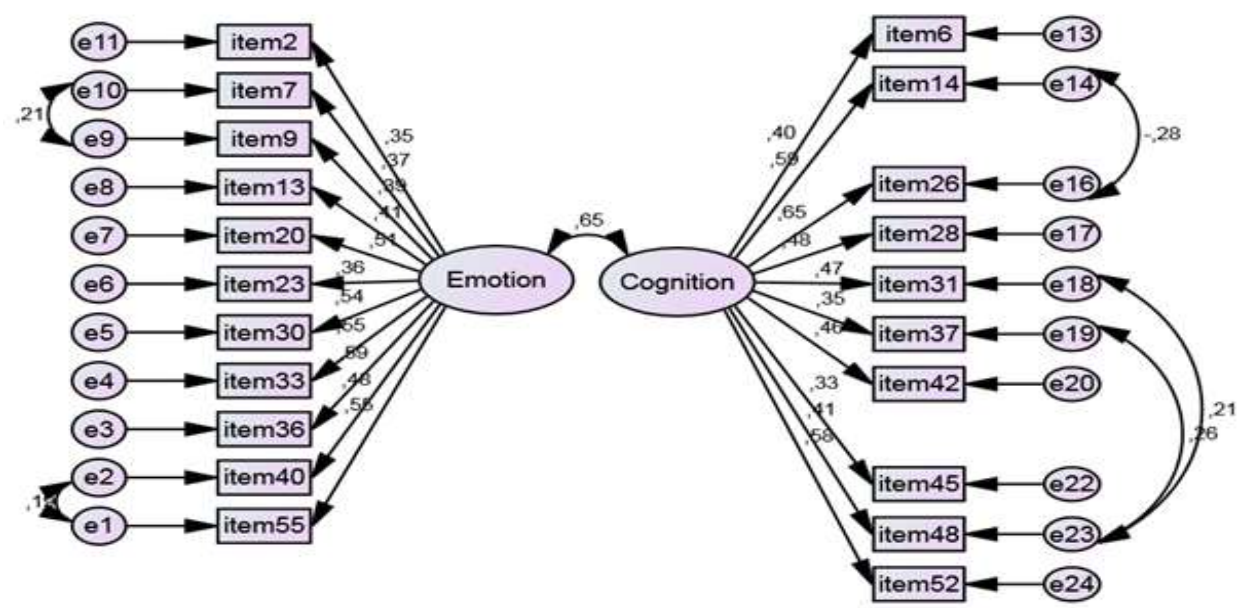

According to the results of explanatory and confirmatory factor analyses, the empathy quotient can be said to have good structural validity. As a result of these analyses, the questions of the Turkish empathy sub quotient form consist of 21 questions, of which the emotional empathy part contains 11 questions $\left(2^{\text {nd }}, 7^{\text {th }}, 9^{\text {th }}, 13^{\text {th }}, 20^{\text {th }}, 23^{\text {rd }}, 30^{\text {th }}, 33^{\text {rd }}, 36^{\text {th }}, 40^{\text {th }}\right.$ and $\left.55^{\text {rd }}\right)$ and the cognitive empathy part contains 10 questions $\left(6^{\text {th }}, 14^{\text {th }}, 26^{\text {th }}, 28^{\text {th }}, 31^{\text {st }}, 37^{\text {th }}, 42^{\text {nd }}, 45^{\text {th }}, 48^{\text {th }}\right.$ and $\left.52^{\text {nd }}\right)$. Systematizing part is preserved as one dimension and 28 questions. Thus, the 49 questions Turkish 
Girli, A., Karadağ, F., \& Karabey, B. (2017). Empathising and systematising in children with and without autism spectrum disorder. Journal of Human Sciences, 14(1), 457-472. doi:10.14687/jhs.v14i1.4242

EQ-SQ is obtained with the empathy sub quotient containing 21 questions and systematizing sub quotient 28 .

Results of the reliability analysis show that the Cronbach alpha value for the "Emotional Empathy Sub Factor" is .752, for the "Cognitive Empathy Sub Factor" .721, for the "Systematizing" quotient .752 and the inner consistency coefficient is high. Since at the omission of any question the change in the alpha value is not big, no changes were made in the arrangement of the questions.

\subsection{Study 2}

In the study, conducted with the second group of children with typical development $(n=80)$ and those with ASC $(n=32)$ with the EQ-SQ quotient, it is examined whether there is a difference between the groups regarding the diagnosis and sex. In the group with ASC, there is no significant difference between females and males in the emotional empathy $(\mathrm{t}=1.644 ; \mathrm{p}=.111)$, cognitive empathy $(\mathrm{t}=1.384 ; \mathrm{p}=.177)$ and total empathy points $(\mathrm{t}=1.648 ; \mathrm{p}=.110)$. Therefore, as in the study with the original quotient, children with ASC are treated as one group when comparing with children with TD.

Table 3. The screening of the difference in EQ-SQ points according to the sex variable.

\begin{tabular}{|c|c|c|c|c|c|c|c|c|}
\hline \multirow[t]{2}{*}{$\mathrm{n}=112$} & \multicolumn{2}{|c|}{$\begin{array}{c}\text { NGG-Female } \\
\quad(n=41)\end{array}$} & \multicolumn{2}{|c|}{$\begin{array}{c}\text { NGG-Male } \\
\qquad(\mathrm{n}=39)\end{array}$} & \multicolumn{2}{|c|}{$\begin{array}{c}\text { ASC } \\
(\mathrm{n}=32)\end{array}$} & \multirow[t]{2}{*}{$\mathrm{F}$} & \multirow[t]{2}{*}{$\mathrm{p}$} \\
\hline & $\mathrm{M}$ & $\mathrm{Sd}$ & $\mathrm{M}$ & $\mathrm{Sd}$ & $\mathrm{M}$ & $\mathrm{Sd}$ & & \\
\hline $\begin{array}{l}\text { Emotional } \\
\text { Empathy }\end{array}$ & 17,39 & 3,25 & 14,54 & 4,59 & 10,31 & 4,97 & 24,72 &, 000 \\
\hline $\begin{array}{l}\text { Cognitive } \\
\text { Empathy }\end{array}$ & 16,85 & 2,69 & 14,43 & 3,46 & 9,40 & 6,41 & 26,72 & ,000 \\
\hline $\begin{array}{l}\text { Total } \\
\text { Empathy }\end{array}$ & 34,17 & 4,87 & 28,94 & 6,89 & 19,71 & 10,41 & 33,07 & ,000 \\
\hline Systematizing & 34,82 & 10,17 & 31,63 & 10,54 & 27,78 & 10,49 & 4,03 & ,021 \\
\hline
\end{tabular}

Upon examining the ANOVA test results, it is seen that there is a significant difference between the Emotional Empathy $(F=24,72 ; p=, 000)$, Cognitive Empathy $(F=26,72 ; p=, 000)$ and Total Empathy $(F=33,07 ; p=, 000)$ points of females with TD, males with TD and children with ASC. Likewise there is significant difference among the points obtained by the systematization quotient $(F=4,03 ; p=, 021)$ as well. The direction of the difference is examined by Bonferroni Test, one of Post-Hoc tests (Figure 4). 
Girli, A., Karadă̆, F., \& Karabey, B. (2017). Empathising and systematising in children with and without autism spectrum disorder. Journal of Human Sciences, 14(1), 457-472. doi:10.14687/jhs.v14i1.4242

Table 4. Screening of EQ-SQ points according to the variable sex (Bonferroni Test)

\begin{tabular}{|c|c|c|c|c|c|}
\hline & & & Mean & & \\
\hline & Sex & Sex & Difference & Std. Error & $\mathrm{p}$ \\
\hline \multirow[t]{4}{*}{ Emotional Empathy } & TD Female & TD Male & $2,84^{*}$ & 96 & ,012 \\
\hline & & ASC & $7,07^{*}$ & 1,00 &, 000 \\
\hline & TD Male & TD Female & $-2,84^{*}$ & 96 & ,012 \\
\hline & & ASC & $4,22^{*}$ & 1,03 &, 000 \\
\hline \multirow[t]{4}{*}{ Cognitive Empathy } & TD Female & TD Male & $2,41^{*}$ & ,98 & ,048 \\
\hline & & ASC & $7,44^{*}$ & 1,02 & 000 \\
\hline & TD Male & TD Female & $-2,41^{*}$ & 98 & ,048 \\
\hline & & ASC & $5,02^{*}$ & 1,04 &, 000 \\
\hline \multirow[t]{4}{*}{ Total EQ } & TD Female & TD Male & $5,23^{*}$ & 1,72 & 009 \\
\hline & & ASC & $14,45^{*}$ & 1,78 & 000 \\
\hline & TD Male & TD Female & $-5,23^{*}$ & 1,72 & ,009 \\
\hline & & ASC & $9,22^{*}$ & 1,82 & ,000 \\
\hline \multirow[t]{4}{*}{ Total SQ } & TD Female & TD Male & 3,18 & 2,40 &, 565 \\
\hline & & ASC & $7,03^{*}$ & 2,47 & ,016 \\
\hline & TD Male & TD Female & $-3,18$ & 2,40 &, 565 \\
\hline & & ASC & 3,85 & 2,525 & ,389 \\
\hline
\end{tabular}

According to the results, females with typical development process have scored significantly higher in Emotional Empathy, Cognitive Empathy and Empathy quotients compared to their male counterparts and children with autism spectrum conditions. As for the systematising quotient, females with TD have scored similar points to their male counterparts and significantly higher than those children with autism spectrum conditions

\section{Discussion and Recommendations}

The adaptation and validity-reliability study results of "Child Empathy Systemizing Quotient (EQ-SQ)" that were obtained from Study 1, which was done in order for children whose native language is Turkish to use, are discussed below. Participants later on taking place in Study 2 have studied whether children with typical development and diagnosed with autism have differences in terms of empathy and systematizing skills. Also, it was studied whether there was a difference with these skills between boys and girls and the conformity of the relevant literature was discussed.

\subsection{Discussion for the Study 1}

The EQ-SQ quotient children form has been developed from an adult empathy quotient whose empathy sub- quotient (EQ) has been prepared in a single factor structure. In this study, firstly an exploratory factor analysis was made in order to identify how many factors the EQ Turkish form consists of. At the end of the analysis, 4,17 and 53 substances under the 0,30 factor load were removed. At the end of the first level DFA analysis done with the remaining substances it was identified that the 24 substances were made up of two sub-factors which are cognitive and emotional empathy. To increase the quotients model suitability substances 1,18 and 43 were removed after looking at their "Standardized Regression Weights" values and according to the DFA results covariance occurred among all of the remaining substances. At the end of the second 
Girli, A., Karadağ, F., \& Karabey, B. (2017). Empathising and systematising in children with and without autism spectrum disorder. Journal of Human Sciences, 14(1), 457-472. doi:10.14687/jhs.v14i1.4242

CFA analysis carried out after these processes, it was found that the $\mathrm{x} 2 / \mathrm{df}$ value was 1.9 regarding the factor structures, which consists of two sub-factors, suitability to the model. The fit indices values were found as BFI: 90, CFI: 92, GFI: 93. When having taken these results into account it can be said that the x2/ df,NFI, CFI, GFI values which belong to the Empathy Quotient confirmatory factor analysis have quite a high level of compliance. As a result, the empathy sub-quotient Turkish form, took its last form with its 21 substances.

Discussions about how many factors empathy consists of continues and in the past few years "social empathy" is brought upon as the third factor of empathy (Falcone et al., 2008). Different results were reached with the studies done by using the EQ quotient adult form. For example, in Allison, Baron-Cohen, Wheelwright, Stone \& Muncer's (2011) studies, is was identified that the single factor was preserved and in some studies, he quotient consists of three factors which are "cognitive empathy", "emotional empathy" and "social abilities" (ex. Andrew, Cooke, \& Muncer, 2008; Muncer \& Ling, 2006; Lawerence, Shaw, Baker, Baron-Cohen, \& David, 2004). With the validity study done within the process of adaptation of the EQ short form to SpanishPortuquese, a three factor structure was obtained the same way (Gouvera, Milfont, Gouvera, Neto,\& Galvão, 2012). In the quotients Turkish adult form factor analysis, a four factor structure consisting of "empathic concern" and "sympathy", "which measures the "cognitive" "social" and "emotional" empathy came up (Bora \& Baysal; akt. Bora \& Baysal, 2009). However, it is thought that "social" empathy, which is defined as "while people are explaining something to some else, maintaining relationships or being kind or rude while criticizing" (Lawrence, Shaw, Baker, BaronCohen, \& David, 2004; Muncer \& Ling, 2006) is a "social" skill and not an "empathy" skill (Gouvera et al., 2012; Muncer \& Ling, 2006). In this study it is seen that the EQ size of the EQ-SQ Turkish form consists of two structures which are generally accepted as "cognitive" and "emotional" empathy. The results obtained from this study, even though there is not yet certain reconciliation is a result similar to the acceptance of the widespread and traditional view that cognitive and social empathy are two dimensions (Baron-Cohen \& Wheelwright, 2004; Gouve1 at al., 2012; Smith, 2006). Systematization sub quotient consists of 28 substances. Like in the original quotient in this study it was used as one size. This way, from the 21 substances that represent the sizes of the empathy sub-quotient emotional and cognitive empathy sizes, a total of a 49 substance Turkish EQ-SQ Quotient whose systematization size consisted of 28 substances, was obtained.

The substance-total correlation of the quotient is at a significant level for "Emotional Empathy Sub-Factor, Cognitive Empathy Sub-Factor" and "Systematization" Quotient. According to the reliability analysis the Cronbach alpha value for "Emotional Empathy Sub-Factor" .752, for "Cognitive Empathy Sub-Factor.721, and for "Systematization" Quotient .752 internal consistency coefficient was found to be high. Due to the change in the alpha value not being high, no changes were made concerning the regulation of substances when any substance was removed. For the original tests Cronbach alpha internal consistency coefficient EQ .93, SQ 0.78; for the Test-Retest Reliability EQ .86, SQ .84. was identified. In a different study (732 participants between ages 12-16) the Cronbach alpha internal consistency coefficient was calculated as EQ $(a=.93)$ and SQ $(a=.78)$ (Auyeung et al., 2012). When we look at these results it can be said that the reliability and internal consistency of the EQ-SQ Turkish form is high. As a result, it can be said that when evaluating the empathy-systematization skills of children between the ages of 9 and 16 whose native language is Turkish, as a quotient tool whose validity and reliability is high, "Turkish Children EmpathySystematization Quotient" (TCESQ) can be used.

It is possible to use the empathy quotient to evaluate cognitive and emotional empathy skills separately. For example, according to the cognitive and emotional empathy sub-factors obtained by a factor analysis carried out by adult EQ Lawrence and his friends (2004), its relationship with the stenotype and social functioning scores have been studied and it has been seen that they may be used for this purpose (Wakabayashi et al., 2006). In the studies carried out for teens, it was used for teens with psychopathology with Asperger syndrome and teens that show normal development Jones et al., 2010). Similarly, it is thought that the empathy sub-quotient Turkish child form can be 
Girli, A., Karadağ, F., \& Karabey, B. (2017). Empathising and systematising in children with and without autism spectrum disorder. Journal of Human Sciences, 14(1), 457-472. doi:10.14687/jhs.v14i1.4242

used as information providing tool within the studies in child psychiatry about cognitive and emotional sub-quotient scores ASC and TD children and some childhoods with psychotic disorders.

\subsection{Discussion for the Study 2 \\ 4.2.1. Discussion for the "Diagnosis" variable}

Due to the fact that there was no significant difference on empathy points between females and males within the ASC group, this group was included into the analysis as a one group. It was seen that children with ASC obtained quite lower points than TD females and males. According to the results of Bonferroni Test, ASC group acquired the lowest score by taking lower points than TD males within the total point obtained from Empathy Quotient and Sub-quotients of Emotional Empathy and Cognitive Empathy. There results were similar with the results of study of Girli \& Tekin (2012) carried out with the TD children between 9 and 16 age by using Empathy Quotient for Children (Bryant, 1982). The similar results were obtained in the studies of Baron-Cohen and Wheelwright, (2004); Wakabayashi et al., (2007). It was seen in the study of Auyeung et al. (2009) that there was a great difference between the points of autistic males and typically developing males with regard to EQ points.

In recent years, the number of results has been increased as autistic individuals experience more problems in the cognitive empathy field than the emotional empathy. For instance, Auyeung et al. (2009) determined in their study that autistic children showed lower performance in the cognitive empathy aspects than the emotional empathy. In other study, the adolescents with Asperger syndrome were compared with the adolescents having pathology and problematic behaviours in the control group, and it was determined that adolescents with Asperger syndrome acquired lower scores than the control group in the field of cognitive empathy in the opposite of adolescents with pathology, however that they took place in average range in the field of emotional empathy. (Jones et al., 2010). In the study carried out by Baron-Cohen (2011); Mazza et al. (2014); Schwenck et al. (2012) and Rueda, Fernández-Berrocal \& Baron-Cohen (2015), similar results were repeated for various ages. It was seen that these results repeated the results of previous studies performed before (Dyck, Ferguson and Shochet, 2001; Dziobeck et al., 2008; Johnson, Filliter and Murphy, 2009; Rogers et al., 2007). In line with the results of the studies performed in the various cultures, it can be said that the children with ASC are incompetent in the skills related to cognitive aspects of empathy rather than the emotional aspect. In this study, it is seen that the cognitive empathy points of children in ASC group $(X=9.40)$ are lower than the emotional empathy points $(X=10.31)$. It is required to repeat this study with larger groups in order to examine these results in our country.

\subsubsection{Discussion for the "Gender" variable}

It was determined that normally developing females obtained higher points than the typically developing males and autistic children (male and female) according to the points obtained from empathy quotient. It was seen that there was a significant difference between the points, and that according to this ranking, TD females were at the top, and then TD males took place and children with ASC diagnosis were in the last rank. This result supports many studies indicating that females are more empathetic than men in the relative literature. For instance, in the study of Auyeung et al., (2009), it was determined that typically developing females acquired higher points than NDP males and autistic group in a significant degree. In the many studies carried out with adult ASC individuals, it was found that females acquired higher scores than the males (Baron-Cohen and Wheelwright 2004; Carroll \& Chiew 2006; Wheelwright et al. 2006). These results were repeated in the multi-cultural studies including general population by means of Wakabayashi et al., (2007) in Japan, (Berthoz et al., 2008) in France, (Preti et al., 2011) in Italy and Bora and Baysal (2009) in Turkey. Girli \& Tekin (2012) compared typically developing children and ASC children in the study carried out with different empathy quotients. It was determined that high-functional autistic females 
Girli, A., Karadağ, F., \& Karabey, B. (2017). Empathising and systematising in children with and without autism spectrum disorder. Journal of Human Sciences, 14(1), 457-472. doi:10.14687/jhs.v14i1.4242

showed higher performance than YFO males. It was observed that females showed remarkably better performances in emotional empathy and sub-quotient of cognitive empathy, and they acquired higher points especially in the sub-quotient of emotional empathy. This result supports the findings indicating that the difference between male and female is more obvious in the articles measuring emotional empathy in the factor analytical studies before (Munser \& Ling, 2006).

According to Empathising-Systemizing literature and research results, it has been mentioned that there are differences on genders from the point of systemizing skills, and that systematizing scores of males are higher than females. For instance, in the studies of Auyeung et al (2009), BaronCohen et al. (2003), Carroll and Chiew (2006) and Wheelwright et al. (2006), it was found out that SQ scores of males were higher than the females. SQ scores of autistic group were higher than both typically developing males and females. In this study, a reverse result was obtained comparing with the studies performed before. The systematizing scores of females with typical development were found very close to those of males with typical development and higher than the group with ASC diagnosis. One of the reasons for this can be cultural. Females in the Turkish culture are educated to perform helping tasks to help their mothers like tidying up the house, picking up things at a young age. For this reason, while mothers evaluate their children, they could have thought in articles like "My child's room is messier than tidy" and "My child takes pleasure in organizing some things (e.g. flowers, books, collections)" that females might have more of these behaviours. Another reason is can be the fact that the number of ASC children is this study is limited. Also, in this study the male-female rate is not compatible with the $5 / 1$ rate. The female rate is $31.2 \%$ and the male rate is $68.8 \%$. It is considered that the results can change in a bigger study group and in situations where the male-female balance is similar to diagnostic distributions. For this reason, it should be examined with the EQ-SQ Turkish form whether or not the works compared by gender in larger sample groups and the findings re-occur.

It is known that the theory of mind and lack of empathy of individuals with ASC cause social and transactional incompetency and that this situation affects positive interaction (Goldstein \& Winner, 2012). It is quite important that the empathy skills of individuals with autism are measured and that there are studies regarding these fields in the education programs. In recent years, it is known that intervention programs are developed in order to developed empathy/ mind reading (cognitive empathy) skills (Hess, Morrier, Heflin, Ivey, 2008). There are many study results that show that individuals with autism benefit more from technology based education materials due to the superior properties they show in their systematizing skills. For example, for individuals who are diagnosed with Asperger syndrome or high-functioning autism, recognition of complex emotions from facial expressions and voices and understanding of mental states teachings were done by using an interactive multimedia technique (Golan \& Baron-Cohen, 2006). For this reason, new programs especially made with new computer technologies are increasing (Howlin, 2008). When looked at from this angle, it is considered that a reliable tool that evaluates the empathysystematization qualities of children with autism and that reflect the results on the intervention programs will be beneficial.

\section{Limitations and Future Directions}

The quotient is designed to evaluate the children through their parents. Upon carrying out the tests, it has been observed that the mothers of children with ASC particularly tend to emphasize the positive features of their children. Therefore, the tendency for more positive notifications on the aspects, which are typical indicators of autistic behaviours, can affect the results of the study. One of the limitations of this study is the insufficient number of children with ASC. It is important to study again with larger study groups from the point of generalization of the results. Furthermore, it is significant to increase the number of participants from the point of decreasing the effects of biased behaviour of mothers. It will be useful to repeat the study 2 with a larger study group in which the male and female balance is similar with the diagnostic balance from the point of systematized results. 
Girli, A., Karadağ, F., \& Karabey, B. (2017). Empathising and systematising in children with and without autism spectrum disorder. Journal of Human Sciences, 14(1), 457-472. doi:10.14687/jhs.v14i1.4242

The validity and reliability of the original form of the quotient was evaluated with the children between 4 and 11 ages. This study was carried out with 9-16 age groups, and it should be generalized for the ages out of this group. This is the other limitation of the results. Examining the validity and reliability of EQ-SQ for TD 4-9 age group speaking Turkish will be useful in order to utilize this Turkish language-adapted quotient and to generalize the results.

The other limitation is that the study is carried out in Izmir. Turkey is a country that has various cultural structures. Therefore, it can be mentioned that the representation level of the results is high for the provinces in the west such as Ankara and Istanbul. The repetition in different provinces will increase the validity and reliability of the quotient. Moreover, it does not cover the children whose native language is not Turkish.

It is considered that Turkish children form of empathy sub-quotient and cognitive and emotional sub-quotient points can used as a tool in order to obtain information on the studies in the field of child psychiatry related to some childhood psychotic disorders, however it is obvious that it is required to study more with larger study groups in order to examine it.

\section{References}

Allison, Baron-Cohen, Wheelwright, Stone, \& Muncer'in (2011). Psychometric analysis of the Empathy Quotient (EQ). Personality and Individual Differences 51, 829-835.

Andrew, J., Cooke, M., \& Muncer, S. J. (2008). The relationship between empathy and Machiavellianism: An alternative to empathizing-systemizing theory. Personality and Individual Differences, 44(5), 1203-1211.

Auyeung, B., Baron-Cohen, S., Ashwin, E., Knickmeyer, R., Taylor, K., \& Hackett, G. (2009). Fetal testosterone and autistic traits. British Journal of Psychology, 100(1), 1-22.

Auyeung, B., Wheelwright, S., Allison,C., Atkinson,M., Samarawickrema,N., Baron- Cohen,S. (2009). The children's empathy quotient and systemizing quotient: sex differences in typical development and in autism spectrum conditions, Journal of Autism and Developmental Disorder. 39:1509-1521.

Auyeung, B., Allison, C., Wheelwright, S., \& Baron-Cohen, S. (2012). Brief report: development of the adolescent empathy and systemizing quotients. Journal of autism and developmental disorders, 42(10), 2225-2235.

Baron-Cohen,S. (2001). "Theory of mind and autism: a review." Special Issues of International Review of Mental Retardation, vol. 23, 169-175.

Baron-Cohen, S. (2002). The extreme male brain theory of autism. Trends in Cognitive Sciences, 6, 248254.

Baron-Cohen, S., Richler, J., Bisarya, D., Gurunathan, N., \& Wheelwright, S. (2003). The systemizing quotient: an investigation of adults with Asperger syndrome or highfunctioning autism, and normal sex differences.Philosophical Transactions of the Royal Society of London B: Biological Sciences, 358(1430), 361-374.

Baron-Cohen, S., \& Wheelwright, S. (2004). The empathy quotient: an investigation of adults with Asperger syndrome or high functioning autism, and normal sex differences. Journal of autism and developmental disorders, 34(2), 163-175.

Baron-Cohen, S., Knickmeyer, R., \& Belmonte, M. K. (2005). Sex differences in the brain: Implications for explaining autism. Science, 310, 819-823.

Baron-Cohen S. (2009). The empathising-systemising theory of autism: implications for education. Tizard Learning Disability Review, 14, 3, 4-10.

Baron-Cohen, S., Lombardo, M. V., Auyeung, B., Ashwin, E., Chakrabarti, B., \& Knickmeyer, R. (2011). Why are autism spectrum conditions more prevalent in males? PLoS Biology, 9, 1-10. 
Girli, A., Karadağ, F., \& Karabey, B. (2017). Empathising and systematising in children with and without autism spectrum disorder. Journal of Human Sciences, 14(1), 457-472. doi:10.14687/jhs.v14i1.4242

Berthoz, S., Wessa, M., Kedia, G., Wicker, B., \& Grezes, J. (2008). Cross-cultural validation of the empathy quotient in a French-speaking sample. Canadian Journal of Psychiatry, 53(7), 469477.

Blacher, J., Kraemer, B., \& Schalow, M. (2003). Asperger syndrome and high functioning autism: research concerns and emerging foci. Curr Opin Psychiatry, 16, 535-542.

Blair, R. J. R (2005). Responding to the emotions of others: Dissociating forms of empathy through the study of typical and psychiatric populations. Consciousness and Cognition, vol. 14, 698-718.

Bora, E. \& Baysal, E. (2009). Psychometric features of Turkish version of empathy quotient in university students. Klinik Psikofarmokoloji Bülteni, vol. 19, 39-47.

Bryant, B. K. (1982). An index of empathy for children and adolescents. Child development, 413-425.

Büyüköztürk, Ş. (2009). Sosyal bilimler için veri analizi el kitabı: İstatistik, araştırma deseni, SPSS uygulamalar1 ve yorum (9. baski). Ankara: Pegem Yaynnlar.

Büyüköztürk, Ş., Kılıç Çakmak, E., Akgün, Ö. E., Karadeniz, Ş. ve Demirel, F. (2014). Bilimsel Arastrma Yöntemleri (18. Baski).Pegem Akademi: Ankara.

Carr, M.B. \& Lutjemeier, J.A. (2005). The relation of facial affect recognition and empathy to delinquency in youth offenders. Adolescence, 40 (159), 601-619.

Carroll, J. M. \& Chiew, K. Y. (2006). Sex and discipline differences in empathising, systemising and autistic symptomatology: Evidence from a student population. Journal of Autism and Developmental Disorders, 36, 949-957. doi:10.1007/s10803-006-0127-9.

Chakrabarti, S. \& Fombonne, E. (2005) Pervasive Developmental Disorders in Pre-school aged children. Confirmation of High Prevalence. A. J. Psychiat. 162, 1133-1144.

Chakrabarti B. \& Baron-Cohen S. (2006). Empathizing: neurocognitive developmental mechanisms and individual differences. Progress Brain Res., 156, 403-417.

Davis M H. (1983). Measuring individual differences in empathy: Evidence for a multidimensional approach. J Pers Soc Psychol 1983, 44, 113-126.

Dyck, M. J., Ferguson, K. \& Shochet, I. M. (2001). "Do autism spectrum disorders differ from each other and from non-spectrum disorders on emotion recognition tests" European Child and Adolescent Psycbiatry, vol.10, pp.105- 116.

Dziobek, I., Rogers, K., Fleck,. Bahnemann, M., Heekeren, H. R., Wolf, O.T., \& Convit, A. (2008). Dissociation of cognitive and emotional empathy in adults with Asperger Syndrome using the multifaceted empathy test (MET). Journal of Autism Developmental Disorders, 38, 464-473.

Falcone, E. M. O., Ferreira, M. C., Luz, R. C. M., Fernandes, C. S., Faria, C. A., D’Augustin, J. F. Pinho, V. D. (2008). Inventário de Empatia (IE): Desenvolvimento e validação de uma medida brasileira [Constrution of a Brazilia measure to evaluate empathy: The Empathy Inventory (EI)]. Avaliação Psicológica, 7, 321-334.

Girli, A. \& Tekin, D. (2012). Investigatıng empathy skill levels of children with autısm and typically developed children between the ages of 9-16. The Journal of Academic Social Science Studies, 5, 8, 603-614.

Goldstein, T. R., \& Winner, E. (2012). Enhancing empathy and theory of mind. Journal of Cognition and Development, 13(1), 19-37.

Gouveia, V. V., Milfont, T. L., Gouveia, R. S., Neto, J. R., \& Galvão, L. (2012). BrazilianPortuguese Empathy Quotient: Evidences of its construct validity and reliability. The Spanish journal of psychology, 15(02), 777-782.

Golan, O., Baron-Cohen, S., Hill, J.J. \& Golan, Y. (2006). The "Reading the Mind in Films" Task: Complex emotion regocnition in adults with and aithout autism spectrum conditions. Social Neuroscience, 1(2), 111-123.

Hambleton, R. K. (2005). Issues, designs, and technical guidelines for adapting tests into multiple languages and cultures. İçinde R. K. Hambleton, P. F. Merenda ve C. D. Spielberger (Ed.). Adapting educational and psychological tests for cross-cultural assessment. New Jersey: Lawrence Erlbaum Associates, Inc. 
Girli, A., Karadağ, F., \& Karabey, B. (2017). Empathising and systematising in children with and without autism spectrum disorder. Journal of Human Sciences, 14(1), 457-472. doi:10.14687/jhs.v14i1.4242

Harari, H., Shamay-Tsoory, S., Ravid, M., \& Levkovitz, Y. (2010). Double dissociation between cognitive and affective empathy in borderline personality disorder. Psychiatry Research, 175, 277-279.

Hess, K. L., Morrier, M. J., Heflin, L. J., Ivey, M. L. (2008). Autism treatment survey: Services received by children with autism spectrum disorder in public school classrooms. Journal of Autism and Developmental Disorders, 38, 961-971.

$\mathrm{Hu}, \mathrm{L}$. ve Bentler, P. M. (1998). Fit indices in covariance structure modeling: Sensitivity to underparameterized model misspecification. Psychological Methods, 3, 424-453.

Howlin, P. (2008). Redressing the balance in autism research. Nature Clinical Practice Neurology, 4(8), 407-407.

Jones, A., Happe', F., Gilbert, F., Burnett, S., \& Viding, E. (2010). Feeling, caring, knowing: Different types of empathy deficit in boys with psychopathic tendencies and autism spectrum disorder. Journal of Child Psychology and Psychiatry, 51, 1188-1197.

Johnson, S. A., Filliter, J. H., \& Murphy, R. R. (2009). "Discrepancies between self- and parentperceptions of autistic traits and empathy in high functioning children and adolescents on the autism spectrum." Journal of Autism Developmental Disorders, 39, 1706-1714.

Kimberley Rogers Æ Isabel Dziobek Æ Jason Hassenstab Æ Oliver T. Wolf Æ Antonio Convit/(2007). Who Cares? Revisiting Empathy in Asperger Syndrome. J Autism Dev Disordor,37:709-715.

Kleinhans, N., Akshoomoff, N. ve Delis, D. (2005). Executive functions in autism and asperger"s disorder: flexibility, fluency and inhibition. Developmental Neuropsychology, 27, 379-401.

Lai, M. C., Lombardo, M. V., Pasco, G., Ruigrok, A. N. V., Wheelwright, S. J., Sadek, S. A., Chakrabarti, B., MRC Aims Consortium, Baron-Cohen, S., (2011). A behavioral comparison of male and female adults with high functioning autism spectrum conditions." PLoS One, vol.6, no.6, e20835, doi:10.1371/journal.pone.0020835.

Lawrence, E. J., Shaw, P., Baker, D., Baron-Cohen, S., \& David, S. (2004). Measuring empathy: Reliability and validity of the empathy quotient. Psychological Medicine, 34, 911924.

Lawson, J., Baron-Cohen, S., \& Wheelwright, S. (2004). Empathising and systemising in adults with and without Asperger Syndrome. Journal of Autism and Developmental Disorders, 34, 301-310.

Liu, D., Wellman, H., Tardif, T. \& Sabbagh, M. (2008). "Theory of mind development in Chinese children: a meta-analysis of false belief understanding across cultures and languages." Developmental Psychology, vol. 44, 523-531.

Mazza, M., Pino, M. C., Mariano, M., Tempesta, D., Ferrara, M., De Berardis, D., et al. (2014). Affective and cognitive empathy in adolescents with autism spectrum disorder. Frontiers in Human Neuroscience, 8, 791.

Minio-Paluello, M. V. Lombardo, B. Chakrabarti, S. Wheelwrigth, \& S. Baron-Cohen, (2009). "Response to Smith's letter to the editor 'emotional empathy in autism spectrum conditions: weak, intact, or heightened?", Journal of Autism and Developmental Disorders, 39, 1749-1754.

Muncer, S. J., \& Ling, J. (2006). Psychometric analysis of the empathy quotient (EQ) scale. Personality and Individual differences, 40(6), 1111-1119.

Pallant, J. (2001). SPSS survival manual: a step by step to data analysis using SPSS. Australia: Allen \& Unwin.

Preti, A., Vellante, M., Baron-Cohen, S., Zucca, G., Petretto, D. R., \& Masala, C. (2011). The empathy quotient: A cross-cultural comparison of the Italian version. Cognitive Neuropsychiatry, 16(1), 50-70.

Rogers, K., Dziobek, I., Hassenstab, J., Wolf, O. T. \& Convit, A. (2007). "Who cares? Revisiting empathy in Asperger syndrome." Journal of Autism Developmental Disorder, 37, 4, 709-715. 
Girli, A., Karadağ, F., \& Karabey, B. (2017). Empathising and systematising in children with and without autism spectrum disorder. Journal of Human Sciences, 14(1), 457-472. doi:10.14687/jhs.v14i1.4242

Rueda, P., Fernández-Berrocal, P. \& Baron-Cohen, S. (2015). Dissociation between cognitive and affective empathy in youth with Asperger Syndrome, European Journal of Developmental Psychology, 12:1, 85-98, DOI: 10.1080/17405629.2014.950221

Schwenck, C., Mergenthaler, J., Keller, K., Zech, J., Salehi, S., Taurines, R., . . Freitag, C. (2012). Empathy in children with autism and conduct disorder: Group-specific profiles and developmental aspects. Journal of Child Psychology and Psychiatry, 53, 651-659.

Shamay-tsoory, S. G., Shur, S., Barca1-goodman, L., Medlovich, S., Harar1, H., Levkovitz, Y. (2007). "Dissociation of cognitive from affective components of theory of mind in schizophrenia", Psychiatry Research, 149(1-3), 11 -23.

Smith, A. (2006). Cognitive empathy and emotional empathy in human behavior and evolution. The Psychological Record, 56, 3-21.

Sucksmith, E., Allison, C., Baron-Cohen, S., Chakrabarti, B., \& Hoekstra, R. A. (2013). Empathy and emotion recognition in people with autism, first-degree relatives, and controls. Neuropsychologia, 51(1), 98-105.

Travis, L., Sigman, M., \& Ruskin, E. (2001). Links between social understanding and social behavior in verbally able children with autism. Journal of Autism and Developmental Disorders, 31(2), 119-130.

Wakabayashi, A., Baron-Cohen, S., Uchiyama, T., Yoshida, Y., Kuroda, M., \& Wheelwright, S. (2007). Empathizing and systemizing in adults with and without autism spectrum conditions: Cross-cultural stability. Journal of Autism and Developmental Disorders, 37(10), 18231832.

Wheelwright, S., Baron-Cohen, S., Goldenfeld, N., Delaney, J., Fine, D., Smith, R. \& Wakabayashi, A. (2006). Predicting Autism Spectrum Quotient (AQ) from Systemizing Quotient- Revised (SQ-R) and Empathy Quotient (EQ). Brain Research, 1079, 47-56.

Völlm, B. A. Taylor, A. N., Richardson, P. ve ark. (2005). Neuronal correlates of theory of mind and empathy:A functional magnetic resonance imaging study in a nonverbal task. NeuroImage; 29, 90 - 98.

Valdiney V. Gouveia, Taciano L. Milfont, Rildésia S. V. Gouveia, Julio Rique Neto, and Lilian Galvão (2012). Brazilian-Portuguese Empathy Quotient: Evidences of its Construct Validity and Reliability. The Spanish Journal of Psychology, Vol. 15, 2,777-782 ISSN 1138-7416.

Yıldırım, A., \& Şimşek, H. (2008). Sosyal Bilimlerde Nitel Araştırma Yöntemleri (6. Baske). Ankara: Seçkin Yayıncılık. 